Article

\title{
Assessing Campylobacter Colonization of Broiler Herds Ante Mortem and Monitoring Campylobacter Contamination Post Mortem by qPCR
}

\author{
Gudrun Overesch *, Katrin Haas and Peter Kuhnert ${ }^{(1)}$ \\ Institute of Veterinary Bacteriology, University of Bern, 3012 Bern, Switzerland; katrin.haas@bluewin.ch (K.H.); \\ peter.kuhnert@vetsuisse.unibe.ch (P.K.) \\ * Correspondence: gudrun.overesch@vetsuisse.unibe.ch; Tel.: +41-0-31-631-24-38
}

Received: 30 June 2020; Accepted: 7 September 2020; Published: 10 September 2020

check for updates

\begin{abstract}
Human campylobacteriosis is the most prevalent zoonosis, with chicken meat contributing substantially to the number of cases. Measures to avoid or at least reduce exposure by meat contaminated with Campylobacter (C.) spp. are needed. With regard to the process hygiene criterion introduced in 2018 for Campylobacter spp. on broiler carcasses, we evaluated the performance of a recently developed quantitative real-time PCR (qPCR) for C. jejuni/coli on random caecal samples and chicken meat. With the qPCR on pooled caecal samples not only C. jejuni/coli positive (69.6\%) versus negative broiler herds (30.4\%) were identified, but herds highly colonized with C. jejuni/coli $(39.4 \%)$ could also be identified. From the chicken meat samples, $8.0 \%$ were positive for $C$. jejuni/coli by qPCR and $0.7 \%$ by enumeration (>10 cfu/g) compared to $58.3 \%$ using cultural enrichment. Given the higher sensitivity, the qPCR method could replace the currently used enumeration method to assess the process hygiene criterion for Campylobacter spp. on broiler carcasses. Moreover, with the qPCR, a reliable identification of $C$. jejuni/coli colonized incoming broiler herds a few days before slaughter is feasible, which provides important information to optimize slaughter processes. Finally, identifying and monitoring herds with high C. jejuni/coli colonization rates could help to individually improve biosecurity measures at farm level, eventually reducing the $C$. jejuni/coli load on chicken meat.
\end{abstract}

Keywords: Campylobacter jejuni; Campylobacter coli; process hygiene criterion; chicken meat; enumeration; campylobacteriosis; slaughterhouse; carcasses

\section{Introduction}

For more than 15 years, human campylobacteriosis has been a major food-borne disease in Europe with more than 240,000 reported cases per year [1]. The extraordinary high socio-economic burden is substantiated by the fact that the notification rate corresponds to an estimated number of about nine million cases of human campylobacteriosis annually in Europe [2]. The disease is mainly caused by Campylobacter (C.) jejuni and to a lesser extent by C. coli with approx. $84 \%$ and $10 \%$ of cases, respectively [1]. The handling, preparation, and consumption of chicken meat is a major risk factor and up to $50-80 \%$ of human cases could be attributed to C. jejuni/coli isolates from the chicken reservoir as a whole [3,4]. A baseline study in 2008 showed that, within the European Union, on average, $75.8 \%$ of broiler carcasses at slaughterhouse are contaminated with Campylobacter spp. [5]. In 2018, broiler meat is still the fresh meat category with the highest contamination rates with C. jejuni/coli (37.5\%) and $26.0 \%$ of tested broiler herds were positive for C. jejuni/coli [1]. C. jejuni/coli are commensal bacteria in the gut microbiota of broilers and colonized animals do not show any signs of disease when getting to slaughter [6]. Incoming C. jejuni/coli positive herds result in C. jejuni/coli positive carcasses and via cross contamination of the processing line in the slaughterhouse, even broiler carcasses of negative 
herds may become positive at the end of the slaughter process [7]. Since the cooling step is not able to totally inactivate $C$. jejuni/coli, the organism remains on broiler meat up to the retail level and thus reaches the consumer [8].

In Switzerland, notified human campylobacteriosis cases slightly decreased from 7688 in 2016 to 7223 confirmed cases in 2019, this corresponds to a decrease in incidence of 92 to 84 cases per 100.000 inhabitants $[9,10]$. Most cases were caused by C. jejuni (2019: $68 \%$ of all cases, in $24 \%$ of cases no distinction was made between $C$. jejuni and C. coli). The typical summer peak occurred in the months of July and August accounting for 1817 cases in 2019. The Swiss poultry meat industry conducts annually approximately 1400 Campylobacter examinations on carcasses and meat from broiler. About $21.8 \%$ of the samples proved to be positive for Campylobacter spp. in 2019.

In 2018, for the first time, regulations concerning Campylobacter spp. were introduced into the European legislation on food safety and hygiene (Commission Regulation (EU) no 2017/1495 on amending regulation EC no 2073/2005 as regards Campylobacter in broiler carcasses). The new process hygiene criterion (PHC) is based on the Campylobacter spp. count on broiler carcasses after chilling. According to this criterion, slaughterhouses have to control, and in cases of non-compliance improve, their hygiene management in the slaughter process and/or the biosecurity measures on the broiler farms if 20 (in 2018 and 2019) out of 50 carcasses show more than $1000 \mathrm{cfu} / \mathrm{g}$ Campylobacter spp. after chilling. This criterion will be tightened in 2020 and 2025 with only 15 and 10 samples allowed to reach this value, respectively. Therefore, identification and control of incoming Campylobacter spp. positive broiler herds before slaughter will get more critically important for slaughterhouses in the future to comply with the European regulation.

With the introduction of the PHC, reliable quantification of the Campylobacter spp. load is of major importance for decision makers, as non-compliance will lead to cost-intensive measures to be taken. The prescribed method given by to legislation is the enumeration according to EN ISO 10272-2:2017. This method is laborious and time consuming, leading to the loss of valuable time before the realization of improved hygiene and biosecurity measures in the production process could take place. Hence, sensitive, reliable, and faster methods in comparison to the enumeration technique are needed. A quantitative real-time PCR (qPCR) that allows an easy, sensitive, and quantitative method for C. jejuni/coli detection in poultry flocks ante mortem by the analysis of faecal, caecal, and boot sock samples was published recently [11]. The technique's efficiency was $93 \%$ and it showed a broad range of linearity down to the detection limit of two genome equivalents in the reaction. There was good correlation between $\mathrm{Ct}$ mean values and cfu/g (correlation coefficient $=0.8732, p<0.0001$ ) in all samples, whether they contained high or low numbers of $C$. jejuni/coli. At the farm level, it could be shown that not only caecal content as the gold standard, but also boot sock samples, analyzed by qPCR is an efficient way to detect and quantify C. jejuni/coli in broiler herds a few days before slaughter. Thereby a sensitive and standardized classification system into negative, low, moderate, or high C. jejuni/coli colonization of broiler herds ante mortem is available.

The aim of this study was to evaluate the qPCR as a tool for systematic monitoring of broiler herds on a random sample over one year to get new insights into the quantitative C. jejuni/coli load and possible differences between broiler herds. Moreover, the qPCR protocol should be evaluated for its application on chicken meat as an alternative to the method for culture-based enumeration of Campylobacter spp. according to EN ISO 10272-2:2017.

\section{Results}

\subsection{Classification of C. jejuni/coli Colonization of Broiler Herds by $q P C R$}

From a total of 484 pooled caecal samples (herds) from 464 (95.9\%) a reliable qPCR result was obtained while in 20 samples the qPCR was inhibited. Nine of the inhibited samples were taken in May, three in June, two in July, and six in November. A total of 141 herds $(30.4 \% ; 26.4-34.7,95 \% \mathrm{CI})$ were negative for $C$. jejuni/coli. One hundred herds turned out to be colonized at low level $(21.6 \%$; 
$18.1-25.5,95 \% \mathrm{CI}), 40$ herds were moderately colonized $(8.6 \% ; 6.4-11.595 \% \mathrm{CI})$ and 183 were identified as highly colonized herds (39.4\%; 35.1-44.0, 95\%CI) (Figure 1$)$.

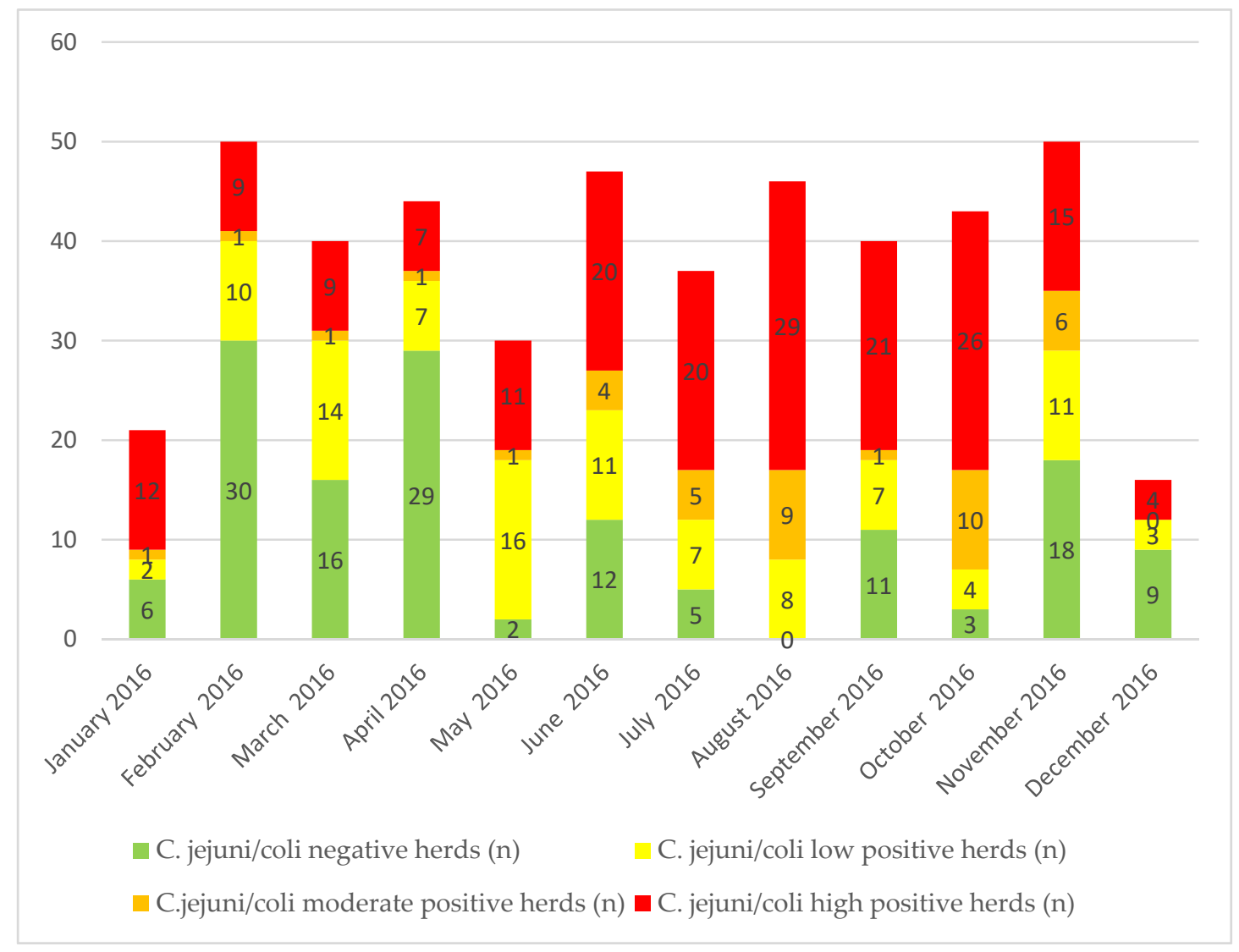

Figure 1. C. jejuni/coli colonization status of pooled caecal samples from broiler herds by qPCR in relation to the sampling date. Numbers in bars indicate number of positive herds. C. jejuni/coli negative herds: $C t$ value $\geq 40 ; C$. jejuni/coli low positive herds: $C t$ value $<40$ to $\geq 35 ; C$. jejuni/coli moderate positive herds: $\mathrm{Ct}$ value $<35$ to $\geq 30 ; \mathrm{C}$. jejuni/coli high positive herds: $\mathrm{Ct}$ value $<30$.

The highest numbers of $C$. jejuni/coli negative herds were observed in February and April, with a decrease until August (Figure 1). In autumn, the number of negative flocks increased again, but at a lower level. The highest numbers of highly positive herds were observed from June to October, with a peak in August. Interestingly, besides this seasonal trend, C. jejuni/coli positive as well as negative herds were observed throughout the year.

When comparing the detection rates of $C$. jejuni/coli positive herds per slaughterhouse the proportion of $C$. jejuni/coli low to high positive herds were found to be lower in the two biggest slaughterhouses 1 and $2(66.3 \% ; 59.4-72.6,95 \% \mathrm{CI}$ and $66.3 \% ; 58.6-73.1,95 \% \mathrm{CI})$ than in the smaller slaughterhouses 3 and 4 (79.4\%; 67.8-87.5, 95\%CI and 79.6\%; 65.5-88.9, 95\%CI) (Table 1). This trend is even more pronounced with the proportion of $C$. jejuni/coli high positive herds, which was much lower in the two biggest slaughterhouses 1 and $2(27.1 \% ; 21.5-33.5,95 \% \mathrm{CI}$ and $37.8 \% ; 30.7-45.4,95 \% \mathrm{CI})$ than in the smaller slaughterhouses 3 and 4 (61.5\%; 49.4-72.4, 95\%CI and 50.0\%; 35.8-64.2, 95\%CI) (Table 1). 
Table 1. C. jejuni/coli colonization status of pooled caecal samples from broilers by qPCR in relation to the slaughterhouse.

\begin{tabular}{ccccccc}
\hline & $\begin{array}{c}\text { C. jejuni/coli } \\
\text { Negative Herds } \\
\mathbf{1}(n)\end{array}$ & $\begin{array}{c}\text { C. jejuni/coli } \\
\text { Low Positive } \\
\text { Herds }^{2}(n)\end{array}$ & $\begin{array}{c}\text { C. jejuni/coli } \\
\text { Moderate } \\
\text { Positive Herds } \\
\mathbf{3}_{(n)}\end{array}$ & $\begin{array}{c}\text { C. jejuni/coli } \\
\text { High Positive } \\
\text { Herds }^{4}(\boldsymbol{n})\end{array}$ & $\begin{array}{c}\text { Caecal Samples } \\
\text { with Inhibited } \\
\text { qPCR }(n)\end{array}$ & $\begin{array}{c}\text { Total Caecal } \\
\text { Samples Per } \\
\text { Slaughter-House } \\
(n)\end{array}$ \\
\hline Slaughter-house 1 & 65 & 47 & 25 & 56 & 14 & 207 \\
\hline Slaughter-house 2 & 54 & 36 & 8 & 62 & 4 & 164 \\
\hline Slaughter-house 3 & 13 & 7 & 3 & 40 & 2 & 65 \\
\hline Slaughter-house 4 & 9 & 10 & 3 & 22 & 0 & 44 \\
\hline Slaughter-house 5 & 0 & 0 & 1 & 3 & 0 & 4 \\
\hline Total & $\mathbf{1 4 1}$ & $\mathbf{1 0 0}$ & $\mathbf{4 0}$ & $\mathbf{1 8 3}$ & $\mathbf{2 0}$ & $\mathbf{4 8 4}$ \\
\hline
\end{tabular}

\subsection{Comparison of C. jejuni/coli Colonization of Broiler Herds by $q P C R$ and by Direct Culture Detection}

For all 484 pooled caecal samples analyzed by qPCR, direct culture detection of $C$. jejuni/coli onto mCCDA was also performed. For 303 samples (62.6\%; 58.2-66.8, 95\%CI), no C. jejuni/coli could be detected while 161 samples (33.3\%; 29.2-37.6, 95\%CI) were positive for C. jejuni/coli (Table 2). All samples negative for $C$. jejuni/coli by qPCR were also negative by culture. From 97 low positive samples by qPCR, only three were positive by culture and from 38 moderate positive samples by qPCR only in two samples $C$. jejuni/coli could be detected by culture. From the 156 qPCR high positive samples, 27 turned out to be negative by direct culture detection.

Table 2. Comparison of the C. jejuni/coli status of broiler herds by qPCR and by direct culture detection.

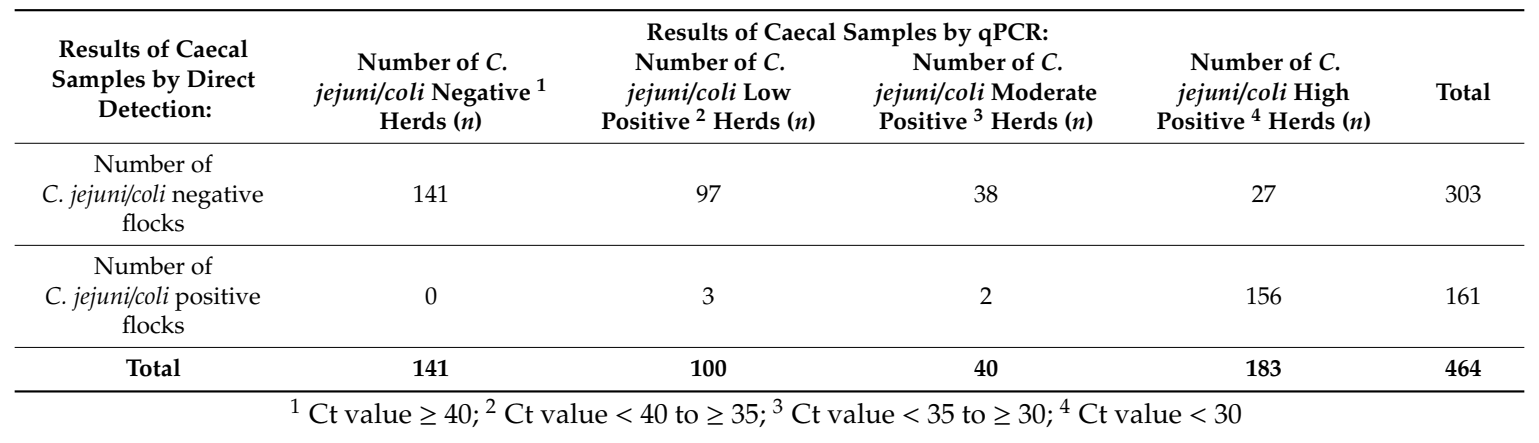

\subsection{Classification of C. jejuni/coli Contamination of Fresh Chicken Meat by $q P C R$}

Between April 2016 and March 2017, a total of 281 fresh retail chicken meat samples were analyzed by qPCR. For 19 samples the qPCR was inhibited (one each in July, October and November, two in September, three in August, 11 samples in May; 15 originated from Switzerland, 4 from other countries). Hence, for 262 samples a qPCR result was obtained (Table 3). In total, 241 out of the 262 samples tested negative for C. jejuni/coli by qPCR $(92.0 \% ; 88.1-94.7,95 \%$ CI). Twenty-one samples were low positive $(8.0 \% ; 5.3-11.9,95 \% \mathrm{CI})$ and distributed over a period from August 2016 until March 2017. According to the sampling plan (two in three samples from Switzerland) from 281 chicken meat samples $194(69 \%)$ were domestic and $87(31 \%)$ originated from foreign countries. Independent of their origin the same proportion of $C$. jejuni/coli negative and positive samples was observed (Table 3). 
Table 3. C. jejuni/coli classification of chicken meat samples by qPCR in relation to the sampling date.

\begin{tabular}{|c|c|c|c|c|}
\hline Sampling Month & $\begin{array}{c}\text { C. jejuni/coli } \\
\text { Negative }^{1} \text { Meat } \\
\text { Samples }(n)\end{array}$ & $\begin{array}{c}\text { C. jejuni/coli Low } \\
\text { Positive }{ }^{2} \text { Meat } \\
\text { Samples }(n)\end{array}$ & $\begin{array}{c}\text { C. jejuni/coli } \\
\text { Moderate Positive } \\
{ }^{3} \text { Meat Samples } \\
\text { (n) }\end{array}$ & $\begin{array}{c}\text { C. jejuni/coli High } \\
\text { Positive }{ }^{4} \text { Meat } \\
\text { Samples }(n)\end{array}$ \\
\hline April 2016 & 28 & 0 & 0 & 0 \\
\hline May 2016 & 16 & 0 & 0 & 0 \\
\hline June 2016 & 18 & 0 & 0 & 0 \\
\hline July 2016 & 24 & 0 & 0 & 0 \\
\hline August 2016 & 18 & 1 & 0 & 0 \\
\hline September 2016 & 25 & 5 & 0 & 0 \\
\hline October 2016 & 14 & 4 & 0 & 0 \\
\hline November 2016 & 16 & 5 & 0 & 0 \\
\hline December 2016 & 12 & 1 & 0 & 0 \\
\hline January 2017 & 23 & 2 & 0 & 0 \\
\hline February 2017 & 22 & 2 & 0 & 0 \\
\hline March 2017 & 25 & 1 & 0 & 0 \\
\hline Total & 241 & 21 & 0 & 0 \\
\hline Swiss origin & 164 & 15 & 0 & 0 \\
\hline Other origin & 77 & 6 & 0 & 0 \\
\hline
\end{tabular}

\subsection{Comparison of the C. jejuni/coli Contamination of Fresh Chicken Meat by qPCR and by Enumeration}

From the 281 fresh chicken meat samples which were analyzed by qPCR, enumeration of C. jejuni/coli was performed in parallel (Table 4). For 19 samples which were inhibited by qPCR, all were negative for $C$. jejuni/coli by enumeration $(<10 \mathrm{cfu} / \mathrm{g})$. Only two samples which showed a negative qPCR result tested positive for C. jejuni/coli by enumeration (>10 cfu/g) $(0.7 \% ; 0.2-2.6,95 \% \mathrm{CI})$ (Table 4$)$. From 239 samples tested negative by enumeration, 21 turned out low positive in the qPCR.

Table 4. Comparison of the C. jejuni/coli status of fresh chicken meat by qPCR and by enumeration.

\begin{tabular}{|c|c|c|c|c|c|}
\hline \multirow[b]{2}{*}{$\begin{array}{l}\text { Results by } \\
\text { Enumeration }\end{array}$} & \multirow[b]{2}{*}{$\begin{array}{c}\text { Number of } C \text {. } \\
\text { jejuni/coli Negative }{ }^{1} \\
\text { Meat Samples }\end{array}$} & \multicolumn{2}{|c|}{ Results by qPCR: } & \multirow[b]{2}{*}{$\begin{array}{c}\text { Number of } C \text {. } \\
\text { jejuni/coli Highly } \\
\text { Positive }{ }^{4} \text { Meat } \\
\text { Samples }\end{array}$} & \multirow[b]{2}{*}{ Total } \\
\hline & & $\begin{array}{c}\text { Number of } C . \\
\text { jejuni/coli Low } \\
\text { Positive }{ }^{2} \text { Meat } \\
\text { Samples }\end{array}$ & $\begin{array}{c}\text { Number of } C \text {. } \\
\text { jejuni/coli Moderate } \\
\text { Positive }{ }^{3} \text { Meat } \\
\text { Samples }\end{array}$ & & \\
\hline $\begin{array}{l}\text { Number of } \\
\text { C. jejuni/coli negative } \\
\text { meat samples } \\
(<10 \mathrm{cfu} / \mathrm{g})(n)\end{array}$ & 239 & 21 & 0 & 0 & 260 \\
\hline $\begin{array}{c}\text { Number of } \\
\text { C. jejuni/coli positive } \\
\text { meat samples } \\
(>10 \mathrm{cfu} / \mathrm{g})(n)\end{array}$ & 2 & 0 & 0 & 0 & 2 \\
\hline Total & 241 & 21 & 0 & 0 & 262 \\
\hline
\end{tabular}

\subsection{Comparison of C. jejuni/coli Contamination of Fresh Chicken Meat by Enrichment and Enumeration}

The 211 fresh chicken meat samples were also analyzed for C. jejuni/coli by enrichment of $25 \mathrm{~g}$ in Preston broth and enumeration in parallel (Table 5). In total, 123 out of the 211 samples tested positive for C. jejuni/coli by Preston enrichment (58.3\%; 51.6-64.7, 95\%CI). In contrast, only two samples were positive for $C$. jejuni/coli by enumeration (71 cfu/g and $13 \mathrm{cfu} / \mathrm{g})(0.95 \% ; 0.3-3.4,95 \% \mathrm{CI})$ (Table 5). These two samples were positive with enrichment, too. 
Table 5. C. jejuni/coli classification of chicken meat samples by Preston enrichment and by enumeration in relation to the sampling date.

\begin{tabular}{|c|c|c|c|c|}
\hline $\begin{array}{l}\text { Sampling } \\
\text { Month: }\end{array}$ & $\begin{array}{l}\text { C. jejuni/coli Negative } \\
\text { Meat Samples by } \\
\text { Enrichment in } 25 \mathrm{~g}(\mathrm{n})\end{array}$ & $\begin{array}{l}\text { C. jejuni/coli Positive } \\
\text { Meat Samples by } \\
\text { Enrichment in } 25 \mathrm{~g}(n)\end{array}$ & $\begin{array}{l}\text { C. jejuni/coli Negative Meat } \\
\text { Samples by Enumeration } \\
(<10 \mathrm{cfu} * / \mathrm{g})(n)\end{array}$ & $\begin{array}{l}\text { C. jejuni/coli Positive Meat } \\
\text { Samples by Enumeration } \\
(>10 \mathrm{cfu} / \mathrm{g})(n)\end{array}$ \\
\hline April 2016 & 12 & 16 & 28 & 0 \\
\hline May 2016 & 8 & 19 & 27 & 0 \\
\hline June 2016 & 11 & 12 & 23 & 0 \\
\hline July 2016 & 6 & 19 & 24 & 1 \\
\hline August 2016 & 11 & 11 & 21 & 1 \\
\hline September 2016 & 14 & 18 & 32 & 0 \\
\hline October 2016 & 9 & 10 & 19 & 0 \\
\hline November 2016 & 10 & 12 & 22 & 0 \\
\hline December 2016 & 7 & 6 & 13 & 0 \\
\hline Total & 88 & 123 & 209 & 2 \\
\hline
\end{tabular}

\section{Discussion}

A key factor for a substantial reduction of $C$. jejuni/coli positive broiler carcasses at slaughterhouse is the colonization level of incoming herds which affects the entire slaughter process eventually resulting in corresponding C. jejuni/coli counts on carcasses [12]. In our study, only $30.4 \%$ of the broiler herds were tested negative for C. jejuni/coli by qPCR and $69.6 \%$ were positive, of which a remarkable proportion $(39.4 \%)$ were highly positive $(\mathrm{Ct}$ value $<30)$ for $C$. jejuni/coli. Previous studies have shown, that a $\mathrm{Ct}$ value of 30 corresponds roughly to $1 \times 10^{5}\left(10^{4}\right.$ to $\left.10^{6}\right) \mathrm{cfu} / \mathrm{g}$ C. jejuni/coli depending on the matrix tested [11,13]. Seasonal trends on C. jejuni/coli prevalence were observed, which follows in general the trends in human campylobacteriosis, with a prominent peak in summer and a second peak around new year eve [1,14]. However, critically important, highly positive herds occurred not only during summer, but also in autumn and winter. Besides the seasonal effect, Campylobacter colonization of broiler flocks varies - at least in Europe-between countries as well, with Norway, Sweden, and Finland showing the lowest prevalence [1]. This raises the question about the differences in management and biosecurity measures between farms with constantly no or low level and high level of intestinally colonized broilers. The colonization of broiler intestine with $C$. jejuni/coli depends on several factors, including breed, animal density, special diet, or access to the outside. [15-17]. Moreover, individual farm characteristics, such as poor biosecurity (e.g., inadequate hygiene measures, access of vectors), the presence of other animal species on the farm, catching and placing measures and management of crates have been shown to increase C. jejuni/coli colonization and excretion rates of broilers [18-21]. With the semi-quantitative approach of our qPCR the most critical, high C. jejuni/coli shedding farms could be identified ante mortem and decision makers could primarily focus on these farms for analyzing and improving biosecurity measures. In Switzerland, a great proportion of broilers are produced on farms with outdoor access, to meet expectations of the consumer for more animal welfare-friendly rearing systems. Since we had no information on the rearing system, future studies could base on our data and investigate, if such farms possibly account for the big proportion of highly positive $C$. jejuni/coli animals. Interestingly, we could observe, that the two biggest slaughterhouses supplied caceal samples with an overall lower proportion of $C$. jejuni/coli positive qPCR results than the two smaller slaughterhouses. This may be due to differences in the farm biosecurity systems, which deliver the broilers. On the other hand, this could point out to different hygiene measures at slaughterhouse when taken the samples. Further studies are needed to prove the underlying responsible factors for this observation. Overall, determination of the incoming C. jejuni/coli load of flocks ante mortem, either in caeca or using boot socks, will help decision makers to identify and optimize the whole process along the farm to fork production line. Recently, EFSA has given an updated review of the most effective control options [22]. Besides some uncertainties while modelling, control options like vaccination, feed and water additives, and discontinued thinning turned out to 
lower the risk for C. jejuni/coli load in broiler caeca. The potential of such an approach was recently shown by Frosth et al. [23], where the prevalence of Swedish Campylobacter spp. positive flocks could be lowered from $15.4 \%$ in 2016 to $4.6 \%$ in 2019 .

Caecal samples were analyzed by direct culture detection for $C$. jejuni/coli in parallel. The prevalence of positive herds $(33.3 \%)$ by direct detection was more than twice as low than the prevalence by qPCR (69.6\%). Full agreement between both methods was achieved for the negative tested samples $(n=141)$. From the 183 samples tested highly positive for $C$. jejuni/coli by qPCR, the vast majority ( $n=156,85.3 \%)$ was also positive by culture. With 27 samples being highly positive by qPCR the detection of $C$. jejuni/coli by culture was not possible. The most likely explanation for this is the occurrence of dead or viable but non-culturable (VBNC) C. jejuni/coli [24]. One could argue that the detection of dead or VBNC C. jejuni/coli is not relevant when focusing on human campylobacteriosis. However, the detection of VBNC or even dead C. jejuni/coli indicates problems with biosecurity measures on farm or slaughterhouse level. Moreover, VBNC might still be capable to induce disease in humans [25]. In nearly all of the samples categorized as low $(n=100,97.0 \%)$ and moderate positive ( $n=40,95.0 \%$ ) by qPCR, the cultural detection failed. This is in line with other studies demonstrating the higher sensitivity of PCR protocols versus culture methods with or without enrichment for C. jejuni/coli in different matrices $[25,26]$. Together with the previously shown highly reliable quantification by qPCR [11], our study corroborated the finding that qPCR turned out to be much more sensitive than the direct detection, not to mention its speed, robustness, and shorter handling time. For decision makers, it is crucial to be aware that the estimated C. jejuni/coli prevalence in Swiss broiler herds determined by the currently used culture based standard method is highly underestimated, especially for herds with low and moderate colonization.

The recently introduced PHC focused on broiler carcasses that are contaminated with more than $1000 \mathrm{cfu} / \mathrm{g}$ Campylobacter spp. as determined by the enumeration method according to EN ISO 10272-2:2017. Therefore, we applied the established qPCR on fresh chicken meat samples as approximation for carcasses in order to evaluate the potential for monitoring C. jejuni/coli contamination at slaughterhouses in comparison to the prescribed cultural enumeration method. It turned out that only two out of 262 chicken meat samples showed $>10$ C. jejuni/coli cfu/g $(0.8 \%)$. These low level contaminated samples $(71 \mathrm{cfu} / \mathrm{g}$ and $13 \mathrm{cfu} / \mathrm{g}$ ) were tested negative by qPCR. Such a discrepancy was not observed with caecal content. We assume that inhomogeneous distribution of bacteria in the initial peptone water suspension together with the small amount of $250 \mu \mathrm{L}$ used for the qPCR might be the reason for the negative qPCR result. On the other hand, 21 out of 262 samples $(8.0 \%)$ were tested low positive for C. jejuni/coli by qPCR only. Based on this performance one can assume that discrepancies between qPCR results in enriched broth compared to results by cultural enrichment would be less pronounced. This result may reflect sufficient sensitivity of the qPCR protocol, but further validation studies on broiler carcasses should be performed to be able to replace the cultural enumeration by qPCR for determination of PHC in the future.

The prevalence and contamination level of fresh chicken meat determined by enumeration $(0.7 \%)$ as well as by qPCR $(8.0 \%)$ seems to be very low, even before the PHC was introduced in 2018. When interpreting these results, one has to take into account that predominantly sliced breast meat without skin was tested, which is known to be less contaminated than meat with skin. However, this finding is somewhat challenged when looking at the results for detection of C. jejuni/coli by enrichment according to EN ISO 10272-1:2017. The prevalence of $C$. jejuni/coli contamination in fresh chicken meat analyzed by enrichment was very high (58.3\%) compared to direct culture and qPCR. This may partially be due to the detection limit of $10 \mathrm{cfu} / \mathrm{g}$ with enumeration. However, since the infection dose for human camplyobacteriosis is very low (approx. $550 \mathrm{cfu})[27,28]$ application of the PHC established now for broiler carcasses at slaughterhouses after chilling might highly underestimate the percentage of relevant $C$. jejuni/coli contaminated broiler carcasses, especially in countries with a low percentage of highly contaminated broiler carcasses (>1000 cfu/g) like Finland, Sweden, or Norway [5]. EFSA estimated that the risk for human campylobacteriosis in Europe will be reduced by $>50 \%$ if 
no slaughter batches achieve the limit of $>1000 \mathrm{cfu} / \mathrm{g}$ on breast and neck skin [1]. On a country level the success for decreasing the number of human cases is highly correlated with the number of batches, which fall below the currently valid PHC. On the European level first data reported from 2018 indicate that approx. $18 \%$ of neck skin samples tested, showed C. jejuni/coli numbers $>1000 \mathrm{cfu} / \mathrm{g}$ [1]. This proportion of heavily contaminated broiler carcasses seems to be low and the development of the reported cases of human campylobacteriosis in Europe will show if it will be effective in lowering substantially the case numbers in the future.

\section{Materials and Methods}

\subsection{Sampling and Samples Preparation}

In 2016, caecal samples were taken from 484 stratified random herds in Swiss poultry slaughterhouses. Caecal samples were collected in the five largest poultry slaughterhouses from 11.01.2016 until 13.12.2016. Every slaughterhouse collected a number of samples proportional to the number of animals slaughtered per year. This procedure ensured that at least $75 \%$ of slaughtered broilers were covered by the sample size. Sampling was spread evenly throughout the year. Five randomly chosen caecal samples per broiler herd were taken. Caecal samples were stored at $4-8{ }^{\circ} \mathrm{C}$ for a maximum of $48 \mathrm{~h}$ before cultivation and at $-80^{\circ} \mathrm{C}$ until the qPCR analyses were performed. The five ceaca from each herd were opened and the content was mixed with sterile instruments to get the pooled caecal sample.

From January to December 2016, 302 chicken meat samples (min. 50 g) were taken from fresh, skinless, chilled, packed without modified atmosphere, minced and not minced and otherwise untreated meat sold at retail level. Samples were collected in all Swiss cantons throughout the year. The applied sampling scheme considered each canton's population density and market shares of retailers. Approximately half of the chicken meat consumed in Switzerland is imported. Hence, imported and domestic chicken meat accounted for approximately one third and two thirds respectively.

\subsection{DNA Extraction and PCR}

DNA extraction for qPCR was done from $250 \mu \mathrm{g}$ of the pooled caecal content using the FastDNA Spin Kit for Soil (MP Biomedicals, Solon, OH, USA) following the manufacturers instruction. For meat samples $250 \mu \mathrm{L}$ of the incubated buffered peptone water solution containing $10 \mathrm{~g}$ chicken meat used for enumeration, was taken for DNA extraction as described above.

Probes and primers for the $\mathrm{qPCR}$ as well as the internal inhibition control used were previously described. [11,13]. The reaction mix consisted of $1 \times$ TaqMan Fast Advanced Mastermix (Thermo Fisher Scientific, Reinach, Switzerland), $300 \mathrm{nM}$ of each primer Ccj_fusA-L1 (GCCTTGAGGAAATTAAAACTGGTATT), Ccj_fusA-L2 (GCCTTGAAGAGATTAAAACAGGGATT), Ccj_fusA-R1 (TTTAAATGCAGTTCCACAAAGCA), Ccj_fusA-R2 (TTTAAACGCTGTACCGCAAAGCA), $200 \mathrm{nM}$ of each FAM-MGB labeled probe Cj_fusA-probe (AAGTCTTTCTATCGTTCC) and Cc_fusA-probe (AAGTCTTTCTATTGTTCC). The Exogenous Internal Positive Control (IPC; Thermo Fisher Scientific, Reinach, Switzerland) with the IPC mix diluted 1:20 and the IPC template diluted 1:100 was included in every reaction. Each sample was tested in duplicates using $2.5 \mu \mathrm{L}$ DNA in a total volume of $25 \mu \mathrm{L}$. In each run five positive controls with 5650 genome equivalents $(\mathrm{GEq}) / \mu \mathrm{L}, 565 \mathrm{GEq} / \mu \mathrm{L}, 56.5 \mathrm{GEq} / \mu \mathrm{L}, 5.65 \mathrm{GEq} / \mu \mathrm{L}$ and $0.565 \mathrm{GEq} / \mu \mathrm{L}$ for creation of the standard curve was included. The samples were run on an ABI 7500 Fast Real-Time PCR System using standard thermal cycling conditions and analyzed with the 7500 software, version 2.0.5 (Thermo Fisher Scientific, Reinach, Switzerland). For all samples, a threshold of 0.02 was set. For each run the standard curve was analyzed for outliers and slope. Standard curves with a slope between -3.58 and -3.10 were used for the analysis. According to the mean $\mathrm{Ct}$ value results samples were categorized as C. jejuni/coli negative (Ct values $\geq 40$ ), C. jejuni/coli low colonized (Ct values $<40$ to $\geq 35$ ), C. jejuni/coli moderately colonized (Ct values $<35$ to $\geq 30$ ) and C. jejuni/coli highly colonized (Ct values $<30$ ) as described by Hass et al. [11]. 


\subsection{Direct and Pre-Enrichment Culturing}

Caecal samples were tested for $C$. jejuni/coli by direct culture detection on modified charcoal cefoperazone deoxycholate agar (mCCDA; Oxoid Ltd., Basingstoke, UK). A loopful of the pooled caecal content was spread onto mCCDA plates. After incubation at $41.5 \pm 1{ }^{\circ} \mathrm{C}$ for $48 \mathrm{~h}$ at microaerobic conditions $\left(5 \% \mathrm{O}_{2}, 5 \% \mathrm{CO}_{2}, 80 \% \mathrm{~N}_{2}\right.$ and $\left.10 \% \mathrm{H}_{2}\right)$. Suspicious colonies were transferred onto tryptone soy agar plates containing 5\% sheep blood (TSA-SB; BD Becton Dickinson, Franklin Lakes, NJ, USA) at $37 \pm 1{ }^{\circ} \mathrm{C}$ for $24 \mathrm{~h}$. Identification of suspicious colonies was carried out by matrix-assisted laser desorption/ionization time-of-flight mass spectroscopy (MALDI TOF MS; Bruker Daltonics, Bremen, Germany) using the direct transfer method according to the manufacturer's recommendations [29].

For enumeration of $C$. jejuni/coli in fresh meat samples the method according to EN ISO 10272-2:2017 was applied. In brief, $10 \mathrm{~g}$ of chicken meat was minced with a scissors and homogenized in $90 \mathrm{~mL}$ buffered peptone water (Axonlab, Bern, Switzerland) with a stomacher (Stomacher 400 circulator, Seward, UK). One $\mathrm{mL}$ of the suspension as well as $100 \mu \mathrm{L}$ of decimal dilutions of the suspension in sterile $0.9 \% \mathrm{NaCl}$ was spread out onto mCCDA plates. After incubation, suspicious colonies were counted and up to five colonies were transferred onto TSA-SB agar plates. Identification was performed as described above.

For the enrichment of $C$. jejuni/coli in fresh meat samples, $25 \mathrm{~g}$ of minced chicken meat was homogenized in $225 \mathrm{~mL}$ Preston broth (Thermo Fisher Scientific, Reinach, Switzerland) with a stomacher. After incubation at $37 \pm 1{ }^{\circ} \mathrm{C}$ for $4 \mathrm{~h}$ and subsequent incubation at $41.5 \pm 1{ }^{\circ} \mathrm{C}$ for $48 \mathrm{~h}$ at microaerobic conditions one loopful of the suspension was spread onto mCCDA plates. After incubation at $41.5 \pm 1{ }^{\circ} \mathrm{C}$ for $48 \mathrm{~h}$, suspicious colonies were transferred onto TSA-SB agar plates. Identification was performed as described above.

Confidence intervals were calculated using the $\mathrm{R}$ (version 3.4.1, www.cran.r-project.org) function binom.test.

\section{Conclusions}

The recently developed qPCR protocol was further evaluated on pooled caecal samples and proved useful for assessing the C. jejuni/coli load of broiler batches shortly before slaughter. This provides an exceedingly helpful tool for decision makers to control and to improve hygiene measures at slaughter. Moreover, knowledge of constantly high shedding farms provides the basis to individually advise them in good biosecurity management, thereby reducing prevalence and load of $C$. jejuni/coli. The qPCR is more sensitive for the quantification of the C. jejuni/coli contamination rate on carcasses than the prescribed cultural enumeration method and could replace it for determination of the currently introduced PHC in the European legislation. As a summarized conclusion, the qPCR is an important and suitable tool to enable reduction of human exposure to C. jejuni/coli contaminated chicken meat, thereby reducing the number of campylobacteriosis cases and improving public health.

Author Contributions: The conceptualization of the study was done by G.O. and P.K.; G.O. wrote the draft; P.K. reviewed and edited the manuscript; K.H. established the molecular method and performed part of the analysis of caecal samples. All authors have read and agreed to the published version of the manuscript.

Funding: This research was founded by the Federal Food Safety and Veterinary Office (FSVO), grant number 4.15.02 and the Institute of Veterinary Bacteriology, University of Bern, Switzerland.

Acknowledgments: We thank Susanne Rickli for cultural analyses and Stefanie Ackermann and Anita Jaussi for molecular analyses.

Conflicts of Interest: The authors declare no conflict of interest.

\section{References}

1. EFSA, E. European Food Safety Authority and European Centre for Disease Prevention and Control The European Union One Health 2018 Zoonoses Report. EFSA J. 2019, 17, e05926. 
2. Havelaar, A.H.; Ivarsson, S.; Löfdahl, M.; Nauta, M. Estimating the true incidence of campylobacteriosis and salmonellosis in the European Union, 2009. Epidemiol. Infect. 2013, 141, 293-302. [CrossRef] [PubMed]

3. Kittl, S.; Heckel, G.; Korczak, B.M.; Kuhnert, P. Source attribution of human Campylobacter isolates by MLST and fla-typing and association of genotypes with quinolone resistance. PLoS ONE 2013, 8, e81796. [CrossRef] [PubMed]

4. Jonas, R.; Kittl, S.; Overesch, G.; Kuhnert, P. Genotypes and antibiotic resistance of bovine Campylobacter and their contribution to human campylobacteriosis. Epidemiol. Infect. 2015, 143, 2373-2380. [CrossRef] [PubMed]

5. European Food Safety Authority. Analysis of the baseline survey on the prevalence of Campylobacter in broiler batches and of Campylobacter and Salmonella on broiler carcasses in the EU, 2008-Part A: Campylobacter and Salmonella prevalence estimates. EFSA J. 2010, 8, 1503.

6. Oakley, B.B.; Vasconcelos, E.J.R.; Diniz, P.P.V.P.; Calloway, K.N.; Richardson, E.; Meinersmann7, R.J.; Cox, N.A.; Berrang, M.E. The cecal microbiome of commercial broiler chickens varies significantly by season. Poult. Sci. 2018, 97, 3635-3644. [CrossRef]

7. Wirz, S.E.; Overesch, G.; Kuhnert, P.; Korczak, B.M. Genotype and antibiotic resistance analyses of Campylobacter isolates from ceca and carcasses of slaughtered broiler flocks. Appl. Environ. Microbiol. 2010, 76, 6377-6386. [CrossRef]

8. Kittl, S.; Korczak, B.M.; Niederer, L.; Baumgartner, A.; Buettner, S.; Overesch, G.; Kuhnert, P. Comparison of genotypes and antibiotic resistances of Campylobacter jejuni and Campylobacter coli on chicken retail meat and at slaughter. Appl. Environ. Microbiol. 2013, 79, 3875-3878. [CrossRef]

9. Bericht zur Überwachung von Zoonosen und Lebensmittelbedingten Krankheitsausbrüchen—Daten 2016. Available online: file:///C:/Users/MDPI/AppData/Local/Temp/Zoonosenbericht_2016_DE.pdf (accessed on 28 June 2020).

10. Bericht zur Überwachung von Zoonosen und Lebensmittelbedingten Krankheitsausbrüchen—Daten 2019. Available online: file://C:/Users/MDPI/AppData/Local/Temp/Zoonosenbericht\%202019\%20DE.pdf (accessed on 28 June 2020).

11. Haas, K.; Overesch, G.; Kuhnert, P.A. Quantitative real-time PCR approach for assessing Campylobacter jejuni and Campylobacter coli colonization in broiler herds. J. Food Prot. 2017, 80, 604-608. [CrossRef]

12. Seliwiorstow, T.; Baré, J.; Berkvens, D.; Van Damme, I.; Uyttendaele, M.; De Zutter, L. Identification of risk factors for Campylobacter contamination levels on broiler carcasses during the slaughter process. Int. J. Food Microbiol. 2016, 226, 26-32. [CrossRef]

13. Schnider, A.; Overesch, G.; Korczak, B.M.; Kuhnert, P. Comparison of real-time PCR assays for detection, quantification, and differentiation of Campylobacter jejuni and Campylobacter coli in broiler neck skin samples. J. Food Prot. 2010, 73, 1057-1063. [CrossRef] [PubMed]

14. Duqué, B.; Daviaud, S.; Guillou, S.; Haddad, N.; Membré, J.-M. Quantification of Campylobacter jejuni contamination on chicken carcasses in France. Food Res. Int. 2018, 106, 1077-1085. [CrossRef] [PubMed]

15. Williams, L.K.; Sait, L.C.; Trantham, E.K.; Cogan, T.A.; Humphrey, T. Campylobacter infection has different outcomes in fast- and slow-growing broiler chickens. Avian Dis. 2013, 57, 238-241. [CrossRef] [PubMed]

16. Babacan, O.; Harris, S.A.; Pinho, R.M.; Hedges, A.; Jørgensen, F.; Corry, J.E. Factors affecting the species of Campylobacter colonizing chickens reared for meat. J. Appl. Microbiol. 2020. [CrossRef] [PubMed]

17. Allain, V.; Chemaly, M.; Laisney, M.-J.; Rouxel, S.; Quesne, S.; Le Bouquin, S. Prevalence of and risk factors for Campylobacter colonisation in broiler flocks at the end of the rearing period in France. Br. Poult. Sci. 2014, 55, 452-459. [CrossRef] [PubMed]

18. Bull, S.A.; Thomas, A.; Humphrey, T.; Ellis-Iversen, J.; Cook, A.; Lovell, R.; Jorgensen, F. Flock health indicators and Campylobacter spp. in commercial housed broilers reared in Great Britain. Appl. Environ. Microbiol. 2008, 74, 5408-5413. [CrossRef]

19. Agunos, A.; Waddell, L.; Léger, D.; Taboada, E.N. A systematic review characterizing on-farm sources of Campylobacter spp. for broiler chickens. PLoS ONE 2014, 9, e104905. [CrossRef]

20. Torralbo, A.; Borge, C.; Allepuz, A.; García-Bocanegra, I.; Sheppard, S.K.; Perea, A.; Carbonero, A. Prevalence and risk factors of Campylobacter infection in broiler flocks from southern Spain. Prev. Vet. Med. 2014, 114, 106-113. [CrossRef]

21. Smith, S.; Meade, J.; Gibbons, J.; McGill, K.; Bolton, D.; Whyte, P. The impact of environmental conditions on Campylobacter jejuni survival in broiler faeces and litter. Infect. Ecol. Epidemiol. 2016, 6, 31685. [CrossRef] 
22. European Food Safety Authority. Update and review of control options for Campylobacter in broilers at primary production. EFSA J. 2020, 18, e06090.

23. Frosth, S.; Lindsjö, O.K.; Niazi, A.; Fernström, L.-L.; Hansson, I. Identification of transmission routes of Campylobacter and on-farm measures to reduce Campylobacter in chicken. Pathogens 2020, 9, 363. [CrossRef] [PubMed]

24. Lv, R.; Wang, K.; Feng, J.; Heeney, D.D.; Liu, D.; Lu, X. Detection and quantification of viable but non-culturable Campylobacter jejuni. Front. Microbiol. 2020, 10. [CrossRef]

25. De Boer, P.; Rahaoui, H.; Leer, R.J.; Montijn, R.C.; Van der Vossen, J.M.B.M. Real-time PCR detection of Campylobacter spp.: A comparison to classic culturing and enrichment. Food Microbiol. 2015, 51, 96-100. [CrossRef] [PubMed]

26. Johannessen, G.S.; Garofolo, G.; Di Serafino, G.; Koláčková, I.; Karpíšková, R.; Wieczorek, K.; Osek, J.; Christensen, J.; Torp, M.; Hoorfar, J. Campylobacter in chicken-Critical parameters for international, multicentre evaluation of air sampling and detection methods. Food Microbiol. 2020, 90, 10455. [CrossRef] [PubMed]

27. Black, R.E.; Levine, M.M.; Clements, M.L.; Hughes, T.P.; Blaser, M.J. Experimental Campylobacter jejuni infection in humans. J. Infect. Dis. 1988, 157, 472-479. [CrossRef]

28. Blaser, M.J.; Engberg, J. Campylobacter. In Clinical Aspects of Campylobacter Jejuni and Campylobacter Coli Infections; Nachamkin, I., Szymanski, C.M., Blaser, M.J., Eds.; ASM Press: Washington, DC, USA, 2008; pp. 99-121.

29. Hsieh, Y.-H.; Wang, Y.F.; Moura, H.; Miranda, N.; Simpson, S.; Gowrishankar, R.; Barr, J.; Kerdahi, K.; Sulaiman, I.M. Application of MALDI-TOF MS systems in the rapid identification of Campylobacter spp. of public health importance. J. AOAC Int. 2018, 101, 761-768. [CrossRef]

(C) 2020 by the authors. Licensee MDPI, Basel, Switzerland. This article is an open access article distributed under the terms and conditions of the Creative Commons Attribution (CC BY) license (http://creativecommons.org/licenses/by/4.0/). 